\title{
TUTORS' ROLE IN TUTORIALS: 'UNPACKING' AND 'REPACKING' DURING THE SEMANTIC JOURNEY
}

\author{
S. L. Hassan \\ Fundani: Centre for Higher Education Development \\ Cape Peninsula University of Technology \\ Cape Town, South Africa \\ e-mail: Hassanl@cput.ac.za
}

ABSTRACT

This empirical and theoretically driven evaluation study enacts Karl Maton's Legitimation Code Theory (LCT) concepts of semantic Gravity and semantic Density in the investigation of tutors' movements downwards ('unpacking') and upwards ('repacking') along the semantic scale, during tutorials.

The findings revealed that the pedagogical strategies adopted by tutors enabled them to strengthen and weaken both SG and SD, for semantic wave construction and cumulative knowledge building. For example, by explaining concepts and using examples, tutors helped tutees move knowledge downwards (SG+, SD-) on the semantic scale. Tutors also moved upwards on the semantic scale (SG-, SD+) by focusing on the application of formulae and supporting tutees in practical experiments. The implications of this study for future tutor training programmes are that while it is important to train tutors on how to teach in semantic waves, academic staff will need to be trained on the same as well.

Key words: tutorials, tutors, Legitimation Code Theory, semantics, programme evaluation, academic staff development

\section{INTRODUCTION}

Evaluating tutorials (see Shaw, Carey and Mair 2008, 706; Coughlan and Stephen 2011, 529) and determining its effectiveness in the enhancement of learning (for example, Thomen and Barnes 2015, 956; Truuvert 2014, 29), has occupied the research agenda of many scholars.

Specifically, it has been important to demonstrate that tutors are generally instrumental in enhancing learning among tutees and that they play a pivotal role in improving the academic performance of tutees (Topping 1996, 339; Comfort 2011, 209; Maynard and Almarzouqi 2006; Ashwin 2006, 656; Carter and Yam 2013, 67), as well as transferring discipline-specific skills to tutees (Smitha and Bath 2003, 155; Underhill and McDonald 2010, 104).

Peer tutoring was found to enhance the achievement of second year tutees during practical assessments in an undergraduate applied science degree programme (Comfort 2011, 207). The results of the Comfort $(2011,210)$ study show that students who were tutored achieved higher 
grades than untutored students from the same year and previous year cohort. On the other hand, Maynard and Almarzouqi (2006) argue that peer tutors are not always able to offer appropriate assistance and require support themselves.

In a study undertaken by Ashwin $(2006,654)$ tutors were asked about their account of tutorials. Their responses indicated that the tutorials helped to facilitate the students' understanding of concepts as well as develop and define new positions on the topic. The tutors' account of tutorials also appeared to be related to their discipline and their own approaches to teaching. The tutors saw their role, not only in terms of promoting thinking and understanding of concepts in the discipline, but also in terms of developing tutees' critical thinking around the discipline. The tutor's role was to relate the tutees' ideas to a wider context, while the tutees' role was to present and critically discuss the evidence (Ashwin 2006, 656).

The gap in the tutoring literature lies in a conceptual analysis of how tutors manage to get it right. The purpose of his article is to analyse the manner in which tutors enhance the learning of tutees during tutorials, by borrowing theoretical tools from Legitimation Code Theory (LCT) (see Maton 2009, 46; Maton 2013; Maton 2014a). Specifically, semantics was applied as an analytical tool to demonstrate how tutors helped tutees build knowledge through the construction of semantic waves.

Semantics is comprised of two code modalities or organizing principles, namely semantic gravity (SG) and semantic density (SD) which may be relatively stronger or weaker along their respective continua. When meaning is related more closely to its context, $\mathrm{SG}$ is stronger $\left(\mathrm{SG}^{+}\right)$; when meaning is related less closely to its context, SG is weaker (SG-). When meanings are more condensed within practice, SD is stronger (SD+); when meanings are less condensed, SD is weaker (SD-) (Maton 2009, 46; 2013, 11; 2014a, 130).

Other studies that applied semantics focussed on a specific subject, for example Chemistry (Blackie 2014, 462), Biology (Mcnaught, Maton, Martin and Matruglio 2013, 50; Martin 2013, 23) and History (Matruglio, Maton and Martin 2013, 45; Martin 2013, 23), and mostly technical accounts of the movements between $\mathrm{SG}+/-$ and $\mathrm{SD}+/ \mathrm{SG}-$ were given.

This study is broad in that it addresses the enactment of semantics during tutorials in various disciplines across departments and faculties within a higher education institution. The descriptions of movements between SD and SG are, therefore, less technical and disciplinespecific than previous studies.

The research question that guided this study was: How do tutors promote learning among tutees through the downwards and upwards movements on the semantic scale in the creation of semantic waves? 
Semantic waves involve recurrent movements in the SG and SD of knowledge (Maton 2013, 12). In this study, an analysis is given of the tutor's role in the creation of semantic waves. The construction of semantic waves was employed in tutorials as a strategy to cultivate a gaze within particular disciplines.

The pedagogical strategies that tutors employed during tutorials are discussed in terms of the manner in which tutees were assisted in moving knowledge downwards (SG+, SD-) and upwards (SG-, SD+) on the semantic scale. One of the arguments put forward deals with the use of mother-tongue education in tutorials. While mother-tongue education in tutorials enabled the downward shift on the semantic scale, the upward movement on the semantic scale could have posed a challenge as the African language equivalent of certain technical terms might be non-existent. In that case, English would have had to be used, and this might have created a barrier to learning amongst tutees who did not speak English as a first language. This research makes an important contribution to knowledge in the field since the role of multi-lingualism, involving English and African languages, in the construction of semantic waves, in order to enhance learning during tutorials in higher education, is not well documented.

Furthermore, in this research, what tutors actually do in tutorials to facilitate learning and enhance understanding is explained in terms of both strengthening SG/weakening SD and strengthening SD/weakening SG, which has not been described in this way before in the tutoring literature. This method of tutoring, using semantics, depends not only on the tutor's knowledge of the subject and the ability to explain concepts by moving from abstract concepts towards concrete, everyday life examples ('unpacking), but also on the ability to move knowledge from concrete real life situations towards abstract theorization ('repacking'). In the tutoring literature there is an over emphasis on how tutors explain abstract concepts by using concrete examples (strengthening SG and weakening SD) (see Ashwin 2006, 659; Shaw, Carey and Mair 2008, 711; Carter and Yam 2013, 65). What is missing in the literature is the role of tutors in enhancing learning by using concrete examples to build abstract, conceptual knowledge, thus weakening SG and strengthening SD, which is a gap that is addressed by this research.

\section{THEORETICAL FRAMEWORK}

Maton $(2013,10)$ describes LCT as a 'sociological toolkit for the study of practice', and defines LCT as follows: 'This approach views the practices and beliefs of actors as embodying competing claims to legitimacy, or messages as to what should be considered the dominant basis of achievement within a social field of practice' Maton $(2009,45)$. 
The semantics dimension of LCT is comprised of two code modalities, or organising principles, namely: semantic gravity and semantic density. The relative strengths of SG and SD can be varied independently to generate a range of semantic codes: (SG+/-, SD+/-) (Maton 2014a,18).

Semantic gravity (SG) may be relatively stronger or weaker along a continuum. Strengthening SG refers to processes that entail moving from abstract or generalized ideas, towards concrete cases where meaning is related more closely to its context. Semantic gravity is weakened when there is movement from the concrete particulars of a case towards generalizations and abstractions where meaning is less closely related to its context (Maton 2014a, 110, Maton 2013, 11). The 'recurrent weakening and strengthening of semantic gravity by moving between concrete examples and abstract ideas' is referred to as a gravity wave (Maton 2014a, 119).

It can be said that SG is important for cumulative learning (Maton 2014a, 122) since a prerequisite for cumulative knowledge is that new knowledge should be built on, and integrated with past knowledge, so that knowledge can be transferred across contexts (Maton 2009, 43). Drawing on examples from professional education at university level and English at secondary school level, Maton $(2009,43)$ used LCT to analyse whether cumulative learning was enabled or not. He concludes that; for cumulative learning to happen, SG must be weakened (knowledge must be less context-dependent). The reasoning behind this conclusion is that when students' understanding is anchored in the context, the facilitation of learning becomes compromised and leads to segmented learning.

Maton (2014a, 123) goes on to state that the key to academic achievement does not lie with stronger or weaker SG, but with extending the range of movement between them. Movement between strengthening and weakening SG provides the conditions necessary for decontextualization and recontextualization of knowledge and thus the potential for cumulative knowledge building (Maton 2014a, 123).

'Semantic density refers to the degree of condensation of meaning within socio-cultural practices...' (Maton 2014a, 129). When SD is stronger (SD+) more meaning is condensed within practice. When SD is weaker less meaning is condensed within practice. Weakening SD occurs when there is movement from highly condensed practice or symbol, to one that involves less meaning, such as explaining a technical concept from an academic source in simpler terms.

The movement of SG and SD inversely to each other results in a semantic scale which Maton (2013, 14) uses to illustrate a semantic wave comprising of a downward shift ('unpacking' knowledge) from abstract (SG-), condensed meaning (SD+) to concrete (SG+) 
simpler meanings (SD-), followed by an upward shift ('repacking' knowledge) that completes the wave back to SG-/SD+.

'Unpacking' knowledge refers to the movement from technicality into more familiar, common-sense language. 'Repacking' knowledge addresses the 'constellations of meanings' that abstract and condensed terms are located within and reconnects concrete examples with more complex meanings (Mcnaught et al. 2013, 51). Maton $(2013,14)$ explains that although the downward shift (SG+/SD-) is pivotal in aligning with students' lived experiences, the upward shift (SG-/SD+) is just as crucial as it helps with addressing the 'constellations of meaning', within which abstract and condensed terms are positioned. Semantic waves, therefore, are a key feature of cumulative knowledge (Maton 2013, 14).

\section{METHODS}

In this study, which was part of a broader evaluation study, qualitative and quantitative data were analysed in accordance with the semantics dimension of LCT. The qualitative data was gathered through face-to-face interviews with six tutors and seven lecturers who were purposefully selected for the study as well as from responses to the unstructured items in a selfadministered questionnaire, which was completed by 896 tutees. The interviews with the tutors ranged between 28 to 52 minutes. The interviews with the lecturers ranged between 30 to 58 minutes. Interviews were recorded using a digital voice recorder, and hand-written notes were taken.

The quantitative data had been collected via structured items, which were designed using a five-point Likert scale, in the aforementioned questionnaire. The main objectives of the questionnaire were to: 1 ) understand the role of tutors in conducting tutorials; 2) determine whether tutors were deemed competent to conduct tutorials and 3) ascertain whether tutorials had an impact on tutees’ learning.

In order for the research question to be addressed, the qualitative data was analysed using categorization and the identification of themes in accordance with semantics. The quantitative data was analysed using descriptive statistics. To allow for simplicity in the reporting of the data, responses in the 'strongly agree' and 'agree' categories were collapsed and reported as 'agree', while responses in the 'strongly disagree' and 'disagree' categories were combined and reported as 'disagree'.

\section{CONTEXT OF THE STUDY}

The study was conducted at a University of Technology in South Africa. Tutors had attended a 
tutor training programme that had been offered either through a centralized model, or a decentralized model, as reported in a previous publication (Hassan 2013, 203). Tutors were undergraduate students from second year upwards.

Several faculties were involved in this study; this included the Faculties of: Applied Sciences, Business and Management Sciences, Education and Social Sciences, Engineering, Health and Wellness, as well as Informatics and Design. The predominant race groups of the tutee respondents were African (69\%) and Coloured (24\%). Whites (5\%), Asians (1\%) and other race groups (1\%) were in the minority. Regarding the tutee respondents' home language; 54 per cent spoke isiXhosa, 22 per cent spoke English, 11 per cent spoke Afrikaans and 7 per cent spoke other African languages. A small minority spoke French (1.6\%) and other languages (3.4\%).

\section{RESULTS AND DISCUSSION}

The results of the study are discussed in terms of the strategies that tutors adopted in moving downwards and upwards on the semantic scale in order to enhance learning among tutees.

\section{Strengthening SG and weakening SD (downward shift and 'unpacking')}

Analyses of classroom practice, as reported by Maton $(2013,14)$, revealed a series of downward semantic shifts from highly condensed and decontextualized ideas (SG-, SD+), towards concrete examples (SG+, SD-). Teachers were repeatedly 'unpacking' and explaining meanings from written sources, thus producing a 'down escalator profile'.

In this study, the 'unpacking' of abstract, condensed meaning was accomplished by the tutors when they explained concepts to the tutees and used everyday examples to enhance understanding. Some lecturer respondents in this study would focus on abstract concepts, for example programming in Engineering, and would explain the terminology. That is, they would go into depth in terms of explaining and moving towards concrete, less condensed meaning, but this had to be reinforced by the tutors during tutorials.

During 'unpacking' tutors moved from (SG-, SD+) to (SD-, SG+) by using simplified, more concrete everyday forms of knowledge to enhance tutees' learning. Maton (2013, 9) explains how '...teaching often involves a repeated pattern of exemplifying and 'unpacking' educational knowledge into context-dependent and simplified meanings.' A predominant focus on the teaching and learning of decontextualized knowledge, for example abstract concepts (weaker SG) culminates in students being incapable of enacting that knowledge in everyday life situations (Maton 2014a, 122-123). 
'Unpacking' entailed the adoption of student-centered pedagogical approaches: tutors were aware that they were meant to facilitate learning rather than to merely disseminate information. The following comment was made to capture this point: 'At first we [tutors] solved the problem for them [tutees] but we were told to make them understand and not give the whole solution; not to spoon-feed them.' A common technique used in the facilitation of learning was to ask questions related to a particular topic and work interactively with the tutees by asking probing questions as well. The challenges associated with facilitation, however, did not go unreported as one tutor explained: 'I ask a question and only one person answers. I ask another question, the same person answers. At times it's demotivating-it seems we wasted the two hours.’

Asking questions allows for the strengthening of SG and the weakening of SD (Blackie 2014, 467). By asking probing questions tutors in this study invited the tutee respondents to shift down the semantic scale, thus weakening SD. Most tutee respondents (70\%) felt that tutors should ask more probing questions to encourage respondents to engage with the content. There was consensus among 61 per cent of tutee respondents that tutors encouraged them to ask questions and discussed or explained concepts without dominating discussions.

Tutors provided an extension to the lectures by explaining concepts to the tutee respondents. That is, they moved down the semantic scale towards less condensed meaning, unpacking educational knowledge, and thus weakening semantic density. For example, a tutor commented as follows: 'We are the follow-up after the lecture. If [tutees] don't understand, the lecturer is not always there for [them]. We as tutors helped the tutees as far as we could ... and explained further to those who were slower.' Another tutor explained: 'Someone reads and I explain the content ... We do an example ... We take a question and they all do the question and then look at the answers, or I do the question and I show them how to do it.'

The tutee respondents verified that tutors were instrumental in promoting an understanding of the subject by providing clear explanations, diagrams, examples and scenarios. Tutees stated that tutors also provided clarification of concepts and referred to many practical examples to ensure that they understood the concepts. Tutors strengthened SG (SG+) by moving towards concrete, everyday examples and scenarios. Strengthening SG occurs when there is movement from abstract concepts to specifying examples (Maton 2014a, 110).

According to the tutee respondents, the following techniques were used by the tutors to enhance their understanding of the subject:

- Tutee respondent 1: 'Clear explanations and diagrams'.

- Tutee respondent 2: 'Many practical examples made me understand better'.

- Tutee respondent 3: 'Being given an example of the task [was beneficial]'. 
- Tutee respondent 4: 'Tutors gave more hands on experience and linked the content to the tutorials'.

The accessing of examples was not always easy though, as is attested to in this statement by a tutor respondent: 'We need more examples - the internet is tricky to look for examples. We use past questions from previous students.' Some tutor respondents complained that there was little support from lecturers in terms of providing examples.

Nevertheless, the tutee respondents were satisfied that the tutors were adept at promoting an understanding of the subject as is shown in the commentary below:

- Tutee respondent 1: 'I now have more understanding of that chapter than before'.

- Tutee respondent 2: 'He explained very well'.

- Tutee respondent 3: 'Getting in depth explanations from someone who is still a student [was beneficial]'.

- Tutee respondent 4: 'I could ask questions and receive an understandable answer'.

- Tutee respondent 5: 'Getting to understand questions and how to tackle them'.

- Tutee respondent 6: 'The tutor made me understand costing more; made the chapters a lot easier'.

Some tutee respondents suggested that tutors could use different techniques, such as letting them explain the work to check their understanding.

Tutors also enhanced the tutee respondents’ understanding of terminology which resulted in a 'better understanding of the work'. By explaining technical terms tutors were thus able to weaken SD. Maton (2013, 14-15) describes a common pattern in classroom teaching as a downward shift from abstract, generalized and condensed meaning, towards concrete, specified and simpler meaning. A characteristic of this downward shift involved explaining technical terms using common-sense language (Mcnaught et al. 2013, 51). Maton (2013, 15) explains that 'translating' a technical term into common-sense understanding will 'reduce its range of meanings', which will allow a point of entry for novices into those meanings.

Matruglio et al. $(2013,40)$ elaborate that the language of textbooks and handouts contain stronger SD (ideas are condensed within terms), while concomitantly possessing weaker SG (knowledge is not context-dependent but deals with more abstract principles). The use of discipline-specific terminology strengthens SD. The technical language is 'unpacked' during explanations (of the text) through the use of concrete examples that strengthen SG. Simpler explanations of the technical terminology in everyday language would weaken SD, thereby creating a downward movement along the semantic scale.

Some tutees were of the opinion that they were better able to understand concepts on their own, through self-directed learning, than with the help of tutors. That is, they were able to 
strengthen SG and weaken SD on their own. One tutee respondent admitted that: 'Sometimes the tutor spent time explaining things that I had already understood. I felt as if I was wasting my time attending such tutorial sessions.' Another tutee respondent indicated that: 'Lecturers just explain things and when I get home I still understand it. I try things on my own at home.' Yet another comment received was: 'I feel that I prefer self-study so tutorial classes weren't helpful to me'.

Tutee respondents perceived visual aids to be important in enabling them to understand the subject. Forty-five per cent of them felt that tutors used visual aids effectively. They called for 'designated time slots for watching videos' and the utilization of different visual aids. The use of visual aids is important in weakening SD (Blackie 2014, 466).

One tutor respondent verified that making the content more visual helped tutees understand the subject: 'I look for a picture on the internet, not just the words'. Some tutors, however, did not use visual aids and therefore could not weaken SD, which resulted in tutees not understanding the work. One tutee respondent complained: 'There were no PowerPoint presentations or anything we could picture in our minds; we just talked and talked and could not understand some of the concepts'.

Further, this study demonstrated that the use of mother-tongue has a bearing on 'unpacking'. This was probably inevitable given the context of the study in which a large percentage of tutee respondents spoke an African language (isiXhosa or isiZulu) as well as Afrikaans. Only 22 per cent of tutee respondents spoke English as a home language. Forty-six per cent of tutees agreed that the tutor was able to explain concepts to them in their mothertongue. A tutor explained that: 'One would write on the board and if a [tutee] did not understand, they would call us individually and we could explain, sometimes in our mother-tongue, which made it easier for them to understand'. Tutors also revised what tutees would have covered in class in a language that tutees would have understood. One tutee respondent stated that: 'I understand the concepts clearly because they (the tutor) explained everything and also in my mother- tongue'.

Given the diversity of the student population within the context of this study, technical language was not the only issue that needed to be considered in the creation of semantic waves; multi-lingualism also played a role. The majority of tutees did not speak English as a first, or an only, language. By using tutees' mother-tongue, tutors helped tutees move knowledge down the semantic scale to strengthen SG and weaken SD.

There are many accounts of the benefits of mother-tongue education. For example: Wildsmith $(2013,120)$ writes on the successful application of multi-lingual glossaries as an 
intervention in the support of students in first year tutorials; Mashiya (2010, 92) reports on enhanced academic performance when the student's home language is used and Paxton (2009, 345) indicates that when mother-tongue education was adopted the barrier to knowledge was removed and new concepts were better understood, which led to deep learning. Blackie’s (2014, 464) argument that concomitantly trying to develop the specialist language (SD+) and the level of conceptual abstraction (SG-) could cause problems, would favour mother-tongue education.

In other studies (Paxton 2009) students exhibited a negative attitude towards isiZulu as part of mother-tongue education. Some of the reasons offered to support this finding were that terms in isiZulu are underdeveloped and many words in English lack an isiZulu equivalent.

\section{Strengthening SG could result in segmented learning}

A tutor (from the Business Faculty) explained that he helped tutees to read ratios and calculate ratios in order to interpret financial statements, and that he had linked these accounting concepts to soccer in order to make it more visual and more understandable. Although the downward shift is important in aligning with students lived experiences, the upward shift is just as crucial as it helps with addressing the 'constellations of meaning' which abstract and condensed terms are positioned within (Maton 2013, 18). Segmented learning is characterized by stronger SG which would constrain the transfer of meaning across contexts (Maton 2009, 44).

In the DISKS project study, reported by Maton $(2013,13)$ the majority of lessons showed repeated downward movements as written texts were being 'unpacked'. Teachers seldom moved upwards into the pedagogical discourse of the subject by 'repacking' everyday examples into technical terms or ideas. Maton $(2013,14)$ argues that this becomes a problem for cumulative knowledge building because knowledge that is too related to specific contexts (SG+, SD-) may be too disconnected to build upon previous knowledge, or be built upon in the future. Both the upward and downward shifts are important in cumulative knowledge building.

\section{Weakening SG and strengthening SD ('repacking')}

Weakening SG is made possible by drawing generalizing principles from the particulars of a specific context (Maton 2014a, 110). A lecturer from the Business Faculty claimed that when tutors taught the subject they used examples and also moved from the 'least complex' to the 'most complex'. This meant that tutors were instrumental in weakening SG and strengthening SD.

Tutors helped tutee respondents increase their semantic range by showing them how to do calculations which would have entailed the transfer of knowledge in different contexts, 
weakening SG. Tutee respondents claimed that, as a result of the assistance they received from the tutors, they were able to work with fractions and learnt different formats for calculations.

The need for weakening SG and strengthening SD was made evident by the responses from tutee respondents. One tutee respondent made the following request: 'I would like to have more practical experiments done so as to improve my own understanding of how to handle laboratory [apparata]. I need to enhance my confidence in working with laboratory equipment.' Another tutee respondent commented that he/she benefitted from tutorials as he/she was 'able to see and touch laboratory materials for the first time'.

Tutors would have needed to help tutee respondents by explaining what was observed during the practicals. They would do this by moving towards the abstract using condensed, technical terms, thus weakening SG and strengthening SD. Similarly, Blackie (2014, 465-466) explicates that appropriate questioning techniques, pertaining to the processes involved in laboratory practicals, can help students move towards greater abstraction, thereby weakening SG.

Further evidence of tutors increasing SD is shown in this statement made by one of the tutee respondents: 'The tutorials are extremely important and beneficial. They provide excellent training in all matters that involve the theory of design. I am happy with all the theory of design tutors I've had during my three years of studies.'

The use of notes in tutorials also helped strengthen SD. In this regard, Mcnaught et al. (2013, 61) argue that teachers need to find a way to make the organising principles of knowledge visible to students by explicitly teaching with discipline-specific language resources (for example texts that reach higher up on the semantic scale) otherwise students might be limited to meanings lower on the semantic scale (SG+, SD-).

According to one tutee respondent: 'The notes which [the tutor] handed out in class does help me a lot to practice for the tests. The notes are well explained and understandable but in order to understand it well you have to practice on your own.' A further statement by a tutee respondent was: 'The most benefit was to be able to summarize notes using key words. By summarizing them is like writing them [according to] your own understanding; in that it was easier to remember them.' Thus, tutee respondents would have been responsible for strengthening SG and weakening SD (SG+, SD-) by working through course notes.

Tutee respondents recommended that notes that were clear, understandable and not too long to be made available to them. Some lecturer respondents reported that they provided support to tutors by giving them course materials, memoranda and notes. This was done in order to equip them for their tutoring role. 


\section{Discipline diversity and semantics, and tutor training}

In terms of discipline diversity as it relates to semantics, (Maton 2014a, 130) points out that condensation may be different in different fields, such as the humanities and sciences. There are degrees of condensation of meanings; if weaker, fewer meanings are condensed; if stronger, more meanings are condensed. Furthermore, academic subjects are made up of complex webs of meaning that are comprised of compositional structures, taxonomical structures and processes. These webs, or constellations, give the specialized terms meaning and it is imperative for students to demonstrate mastery of this. Thus, the upward climb ('repacking') depends on the subject, and the semantic range for that subject (Maton 2013, 18).

Hierarchical knowledge structures would show weaker SG than horizontal knowledge structures (Maton 2009, 45). Drawing on the teaching of Chemistry to illustrate this point, Blackie $(2014,467)$ explains that one has to work at a relatively high level of abstraction and that this can be attributed to the hierarchical nature of the knowledge structure of Chemistry. Blackie $(2014,466)$ argues that, in the teaching of Chemistry, weakening SG tends to be more challenging than strengthening SD.

The strengthening or weakening of SG and/or SD is discipline-specific. This is portrayed in the comment made by a tutee respondent: 1) 'The amount of work covered in the tutorial needs to be less so as to have a more focussed tutorial session, especially with life sciences where there is so much packed into a small amount of work'. This statement reiterates the point that semantic density is different in different subjects and that the semantic range will also differ across disciplines. This would have implications for the tutor's role in tutorials.

Hence, the role of the tutor in transferring discipline-specific skills to students during tutorials becomes important and has been alluded to by other researchers (Underhill and McDonald 2010, 104). They make the argument that the tutor's role as facilitator of learning should occur within the context of the subject content and discourse. Therefore, the training of tutors should take place within the mainstream disciplines; that is, tutor training should be discipline-specific.

The selection of tutors for training, and ultimately their recruitment, would be contingent on their ability to weaken SG and strengthen SD, as is exemplified by the following suggestions from tutee respondents: 1) 'Only take [tutors] who have good knowledge of the subject and enough skills to explain them to [tutees]'; 2) 'Tutors must be trained by qualified people before coming to [tutees] to see if they know the subject very well and can help [tutees] to understand it as well'. One of the lecturer respondents suggested that only tutors who are more qualified in 
the field and have more experience be recruited.

\section{Preference for tutors over lecturers}

That tutors were helpful in promoting learning among tutee respondents is shown by these comments: 'I understand them better in class. My lecturer does not cover everything and is not well organised.' 'Whenever I did not understand what the lecturer had said in the previous class, I would ask the tutor to explain especially when starting a new chapter.' Tutee respondents felt more comfortable asking the tutors for help during the tutorials than they did lecturers during class time. For instance, one tutee respondent stated: 'The most benefit was that things that I couldn't understand well during lecturing classes, I did understand after tutorial classes'. Another tutee respondent put it succinctly: 'To get something from a [tutor] is much better than to get it from a lecturer'. Another tutee respondent stated that: 'I understand tutors more than I do in class because they further elaborate and give a clear vision of what the lecturer has taught me'. Yet another statement received was: 'Tutors are really helping us a lot; they make us understand the concepts better when we couldn't understand in class'. Tutee respondents felt that tutorials helped them understand the work that was not explained properly by the lecturer.

Seventy-three per cent of tutee respondents were of the opinion that tutors were able to teach well. One tutee respondent elaborated: 'I understand the tutors more than [when] I listen in class because they elaborate and give a clear vision of what the lecturer has taught me'. Many lecturer respondents confirmed that tutees appreciated tutors and the support they provided. One of them admitted that tutees respond better to tutors as they were free to ask questions and point out areas of difficulty.

About half (52\%) of the tutee respondents did not feel that the tutors' knowledge of the subject needed to be improved and many of them (59\%) felt that tutors were able to help them with their academic problems. A lecturer respondent from the Business Faculty was satisfied that the tutor she worked with had 'more than adequate knowledge' to be able to assist tutees.

Various pedagogical methods were applied in supporting learning among tutees. This involved student-centered, and teacher-centered approaches, depending on what was needed to promote understanding among tutees. The tutee respondents indicated that the teaching strategies adopted during tutorials were group work, self-directed learning and one-on-one consultations with tutors. In general, the tutors were applauded for explaining concepts well enough to enhance tutees' understanding of the subject.

In some instances, respondents were not convinced that tutors were effective. One of the lecturer respondents from the Health and Wellness Faculty commented that her subject is visual 
and that students struggle to interpret visual information, but tutors who are only at second year level themselves were not able to explain the information to tutees. From the perspective of the tutee respondents, only a minority (41\%) felt that the tutors were able to answer questions posed to them.

A few tutee respondents felt that lecturers would be more adept at 'unpacking' than the tutors: 'Lecturers should explain the lessons before letting tutors do the rest. I understand better when the lecturer speaks because he knows the stuff better and knows how to transmit his knowledge to us better than the tutor. Tutors in general do not have all the lecturing skills at the beginning so do not let them explain chapters.'

A lecturer respondent from the Engineering Faculty claimed that tutors sometimes told the tutees the 'wrong thing', and that tutees would come to her afterwards for an explanation of the concept. She explained that tutors had a tendency to 'forget the content', especially in mathematics, and needed to attend her class to refresh their memory. Tutors needed to be trained on how to find information and improve discipline knowledge. In this regard, Topping (1996, 325) argues that the tutor's mastery of content is likely to be less than that of a professional teacher.

What must be taken into account is that a specific semantic code may dominate the rules of the game yet may not be transparent. There may be more than one code present, and there might be a struggle over which code is dominant. This leads to degrees of code matching or code clashing among the stances of actors within the field, or between pedagogical practices and the disposition of learners. Actors struggle for control over the semantic device in order to enhance the legitimacy of the semantic codes that characterizes their own stances. Whoever controls this device establishes the semantic structure of the field (Maton 2014a, 132). In this study, tutors were generally viewed as being better than lecturers at enhancing learning among tutee respondents, even if some lecturers perceived them as not being competent enough to facilitate learning. This was most probably due to the ability of tutors in 'unpacking' and 'repacking' knowledge which would have led to a better promotion of learning. It can therefore be said that when it came to tutoring, tutors controlled the semantic device in tutorials and established the semantics of the tutorials.

\section{CONCLUSION}

This article applied the LCT concepts of sematic gravity and semantic density to investigate how tutors moved upward and downwards along the semantic scale to make semantic waves as part of cumulative knowledge-building in tutorials. The strategies employed by tutors in the 
creation of semantic profiles by strengthening and weakening SG and SD through movements downwards and upwards on the semantic scale were discussed. By 'unpacking' and 'repacking' knowledge in upwards and downwards movements on the semantic scale, tutors were instrumental in the creation of semantic waves, which is a crucial aspect of the enhancement of learning.

Tutors viewed their role in terms of promoting an understanding of the subject and provided an account of how this was achieved. Tutors attended to tutees' questions and explained difficult concepts to ensure that the knowledge was understood. This meant providing in-depth help within the discipline and addressing previous knowledge which tutees had a tendency to forget. They also worked through previous examination questions. Therefore, on the semantic scale tutors shifted from context-independent, condensed meanings that is characteristic of theoretical knowledge to context-dependent, simpler meanings as characterized by practical knowledge (see Maton 2014b). Tutors were thus adept at helping tutee respondents in 'unpacking' knowledge in movements downwards on the semantic scale. They had an advantage over lecturers in that they were able to engage with tutee respondents in their mother-tongue language which strengthened their ability to 'unpack' knowledge.

In order to move upwards on the semantic scale tutors made use of texts, the internet and lecturers' course notes. Tutors also focussed on how to use formulae, do calculations and support tutees in practical experiments as part of 'repacking' in the upward movement along the semantic scale. Therefore, tutors helped tutees increase their semantic range. The challenge in adopting mother-tongue education in 'repacking' was that the mother-tongue equivalent did not always exist.

Recommendations for improvement of tutorials that would emanate from this study would entail tutors being empowered to invite tutees to create semantic waves during tutorials. Tutor training programmes that focus on empowering tutors to be facilitators of learning, thus requiring them to ask probing questions, will go a long way in guiding tutors in the creation of semantic waves and expanding the semantic range in order to build knowledge. The training should lean towards the implementation of student-centered pedagogies that require the facilitation of authentic learning, such as: case studies; simulations; role play; problem-based learning; project-based learning; and so forth.

While it is important to train tutors on how to teach in semantic waves, lecturers will need to be trained on the same as well. There should, therefore, be a joint academic staff development and discipline-specific tutor training initiative that incorporates the semantic dimension of LCT.

Some of the implications of this research for higher education in general are given as 
follows: 1) The application of the principles of semantics in teaching and learning might help change the perception of the university as an ivory tower that focusses too heavily on abstract theoretical concepts that are difficult to apply in real life contexts; 2) The ability of tutors to ride semantic waves will allow for greater epistemological access and would potentially improve pass rates and throughput rates; 3) That tutors might be more adept at teaching than lecturers needs to be acknowledged and capitalized upon so that lecturers can be 'freed' to utilize their limited time more effectively by engaging in research; 4) Lecturers, who have more knowledge of the discipline, will need to work more collaboratively with tutors especially in terms of helping them strengthen SD. This could affect the power dynamics between lecturers and tutors who might be viewed more as equals; 5) Tutors could play a pivotal role in curriculum design because of their ability to ride semantic waves by oscillating between concrete experience and abstract conceptualization; 6) The challenge of implementing the principles of semantics in higher education, however, is that tutors (and lecturers) will need to have both functioning knowledge and conceptual knowledge in order to be effective teachers which would require both extensive experience in the field in addition to a high level academic qualification.

A limitation of this study was that a small sample of tutors and lecturers was involved and, this was a broad study that involved multiple disciplines across an institution. What is further needed is a study of the manner in which tutors create semantic waves in the various disciplines. This study briefly illustrated the notion of differential semantic wave construction pertaining to various disciplines, and additional exploration in this area could be undertaken.

Other avenues for future research include the role of multi-lingualism in the construction of semantic waves since this is not well documented, and is worthy of more extensive investigation.

As mentioned previously in this article, tutors are often acknowledged for their phenomenal pedagogical role in tutorials. This study offered some insight into the way in which this is achieved.

\section{ACKNOWLEDGEMENT}

This research was conducted at the Cape Peninsula University of Technology, Cape Town, South Africa.

\section{REFERENCES}

Ashwin, P. 2006. Variation in academics' accounts of tutorials. Studies in Higher Education 31(6): 651665.

Blackie, M. A. L. 2014. Creating semantic waves: Using Legitimation Code Theory as a tool to aid the 
teaching of chemistry. Chem. Educ. Res. Pract.15: 462-469.

Carter, A. and S. Yam. 2013. How can tutors engage property students in controlled teaching environments? Experiences of a new academic. Property Management 31(1): 55-75.

Comfort, P. 2011. The effect of peer tutoring on academic achievement during practical assessments in applied sports science students. Innovations in Education and Teaching International 48(2):207211.

Coughlan, J. and S. Stephen. 2011. Student and tutor perceptions of learning and teaching on a first-year skills module in a university computing department. Educational Studies 37(5): 529-539.

Hassan, S. 2013. Evaluation of a tutor training programme through the frame of activity theory. In Research and development in higher education: The place of learning and teaching, ed. S. Frielick, N. Buissink-Smith, P. Wyse, J. Billot, J. Hallas and E. Whitehead, 36, 200-212. Auckland, New Zealand, 1-4 July 2013. Published by the Higher Education Research and Development Society of Australasia, Inc.

Martin, J. R. 2013. Embedded literacy: Knowledge as meaning. Linguistics and Education 24: 23-37.

Mashiya, N. 2010. Mother tongue teaching at the University of KwaZulu-Natal: Opportunities and threats. Alternation 17(1): 92-107.

Maton, K. 2009. Cumulative and segmented learning: Exploring the role of curriculum structures in knowledge-building. British Journal of Sociology of Education 30(1): 43-57.

Maton, K. 2013. Making semantic waves: A key to cumulative knowledge building. Linguistics and Education 24(1): 8-22.

Maton, K. 2014a. Knowledge and knowers: Towards a realist sociology of Education. New York: Routledge.

Maton, K. 2014b. Building powerful knowledge: The significance of semantic waves. In The future of knowledge and curriculum, ed. E. Rata and B. Barrett. London: Palgrave Macmillan.

Matruglio, E., K. Maton and J. R. Martin. 2013. Time travel: The role of temporality in enabling semantic waves in secondary school teaching. Linguistics and Education 24:3 8-49.

Maynard, J. and I. Almarzouqi. 2006. Investigating peer tutoring. ELT Journal 60(1): 13-22.

Mcnaught, L., K. Maton, J. R. Martin and E. Matruglio. 2013. Linguistics and Education 24: 50-63.

Paxton, M. I. J. 2009. 'It's easy to learn when you using your home language but with English you need to start learning language before you get to the concept': Bilingual concept development in an English medium university in South Africa. Journal of Multilingual and Multicultural Development 30(4): 345-359.

Shaw, L., P. Carey and M. Mair. 2008. Studying interaction in undergraduate tutorials: Results from a small scale evaluation. Teaching in Higher Education 13(6): 703-714.

Smitha, C. and D. Bath. 2003. Evaluation of a networked staff development strategy for departmental tutor trainers: Benefits, limitations and future directions. International Journal for Academic Development 8(1-2): 145-158.

Thomen, C. and J. Barnes. 2005. Assessing students' performance in first-year university management tutorials. South African Journal of Higher Education 19(5): 956-968.

Topping, K. J. 1996. The effectiveness of peer tutoring in further and higher education: A typology and review of the literature. Higher Education 32: 321-345.

Truuvert, T. 2014. Enhancing tutorial learning experiences: A programme to develop sessional-tutor teaching skills by raising awareness about learning. Studies in Higher Education 39(1): 20-33.

Underhill, J. and J. McDonald. 2010. Collaborative tutor development: Enabling a transformative paradigm in a South African University. Mentoring \& Tutoring: Partnerships in Learning 18(2): 91-106.

Wildsmith, R. 2013. The African languages in South African education 2009-2011. Language Teaching 46(1): $120-124$. 